\title{
PENERAPAN TEKNIK PARALLEL IMAGING PADA PESAWAT MRI 0,35 TESLA UNTUK OPTIMALISASI KUALITAS INFORMASI ANATOMI PADA MRI LUMBAL PEMBOBOTAN T1WI DAN T2WI POTONGAN SAGITAL
}

\section{SELECTING PARALLEL IMAGING TECHNIQUES APLLIED ON THE MRI 0.35 TESLA TO OPTIMISE THE CLINICAL QUALITY OF T1WI AND T2WI FROM LUMBAR SPINE MRI SAGITTAL VIEW}

\author{
Gatot Murti Wibowo ${ }^{1)}$, Dartini ${ }^{2)}$, Hari Prayitno ${ }^{3)}$ \\ ${ }^{1,2,3)}$ Health Polytechnics of Semarang-Indonesia \\ e-mail :wgatotmurti@yahoo.co.id
}

\begin{abstract}
Background : Parallel imaging is one of the MRI Scanning techniques used to reduce the overall scan time when the patients with unvoluntary movement being examined with a low magnetic field of $0,35 \mathrm{~T}$. This research aims to determine the difference between the clinical image quality of the conventional turbo spin echo (TSE) with mSENSE and that of the TSE with GRAPPA parallel imaging techniques from which resulting the MRI T1 and T2 Weighted Images (T1WI and T2WI) sagittal view of lumbar spines, and to define the techniques that clinically provide the most approriate anatomical information.

Methods : This experimental study is made performed by the MRI $0.35 \mathrm{~T}$ in which 10 patients who had hernia nucleus pulposus (HNP) desease participated in the experiments ramdomly. The appointed Radiologists blended in the image evaluation using an image checklist to assess the visualisation of anatomical organs on the resulted sagittal lumbar MRI T1WI and T2WI. The two non-parametric statistical tools, Friedman test and the post hoc Wilcoxon matched pairs test, is used to analyze all the data descriptively. Testing the resesearch hypotheses with $95 \%$ of confident interval is to proved the differences between resulted sagittal lumbar MRI T1WI and T2WI..

Results : The results shown there is a significant difference on the image quality of anatomical information when conventional TSE, parallel imaging-mSENSE and -GRAPPA, with T1WI are applied in the imaging techniques. When those imaging techniques are employed to obtain T2WI, the result is not significant in contrast.

Conclusion : Good imaging techniques with adequate clinical image quality are ranked sequently as the conventional TSE, the mSENSE and GRAPPA.
\end{abstract}

Keyword : Turbo spin echo (TSE), parallel imaging mSENSE, GRAPPA, T1WI-T2WI

\section{PENDAHULUAN}

Kelainan-kelainan patologis yang biasanya menyerang vertebra lumbal antara lain karena kelainan bawaan (scoliosis, kyphosis, hemangioma, spondylolisthesis, lipomatesis, lipoma, bony malformation), trauma dan fraktur, degeneratif disorder (hernia nukleus pulposus, osteochondrosis, spondylo arthrosisi, foramina stenosis), inflamasi (spondylitis, spondylidiscitis, myelitis, multiple sclerosis), tumor dan kelainan pasca operasi (Weyreuther, 2006).

Kelainan-kelainan pada Lumbal dapat didiagnosa dengan pemeriksaan radiologis, antara lain foto polos vertebra lumbal, myelografi, CT Scan maupun MRI. Myelografi pemeriksaanya bersifat invasif, sedangkan pemeriksaan MRI bersifat non invasif dan tidak menggunakan radiasi pengion, oleh karena itu MRI merupakan gold standard dalam mendiagnosa kelainan pada lumbal, terutama HNP.

Dalam dekade terakhir, salah satu cara untuk menurunkan scan time adalah dengan metode parallel imaging. Parallel MRI merupakan teknik canggih untuk meningkatkan kecepatan akuisisi data MRI dengan melewati beberapa garis phase encoding pada $k$-space sementara arah frekuensi encoding tetap disampling penuh (Wang, 2010). Parallel MRI bekerja dengan mengambil keuntungan dari sensitivitas informasi spasial yang melekat dalam beberapa elemen receiver coil untuk menggantikan sebagian waktu spasial encoding, yang biasanya dilakukan dengan mengubah gradien medan magnet (Blaimer dkk, 2004).

Menurut Blaimer (2004), metode rekonstruksi Paralel MRI secara garis besar dapat diklasifikasikan menjadi dua kelompok, yaitu rekonstruksi yang berlangsung di ruang gambar (image space) misalnya, SENSE, PILS dan rekonstruksi yang dilakukan di k-space misalnya, SMASH, GRAPPA. Dari sekian metode rekonstruksi paralel MRI, metode yang dipromosikan oleh vendor-vendor umumnya hanya dua, yaitu SENSE dan GRAPPA yang istilahnya berbeda-beda pada masing-masing vendor.

Reduksi scan time dalam parallel imaging memiliki beberapa manfaat. Pertama, sangat berguna untuk sekuens yang tergantung pada waktu scanning pendek seperti single breath hold. Kedua, waktu pemeriksaan keseluruhan dapat dikurangi, terutama pada pasien dengan keluhan nyeri yang hebat pada posisi tertentu seperti nyeri saat berbaring, pada pasien anak-anak atau pada kasus-kasus emergensi. Selain itu, scan time yang pendek juga dapat memberikan manfaat masalah biaya (Nölte, 2008).

Di Instalasi Radiodiagnostik RSUD Prof. Dr. Margono Soekarjo Purwokerto, pemeriksaan MRI terbanyak adalah pemeriksaan MRI Lumbal dengan kasus HNP. Pesawat MRI 
yang digunakan adalah merk Siemens Magnetom C! 0,35 Tesla. Berdasarkan studi pendahuluan yang penulis lakukan di Instalasi Radiodiagnostik RSUD Prof. Dr. Margono Soekarjo Purwokerto, protokol rutin yang digunakan pada pemeriksaan MRI Lumbal adalah sekuens TSE (Turbo Spin Echo) untuk pembobotan T1 Sagital, T2 Sagital serta T2 Transversal dan sekuens SE (Spin Echo) untuk pembobotan T1 Transversal. Kemudian percobaan sederhana dilakukan dengan menerapkan kedua teknik iPAT di atas, yaitu mSENSE dan GRAPPA pada pemeriksaan MRI Lumbal khususnya untuk sekuens TSE, karena pada sekuens SE, iPAT tidak bisa diterapkan. Hasilnya secara kasat mata terdapat perbedaan tetapi tidak begitu mencolok jika dibandingkan dengan hasil citra yang dihasilkan tanpa teknik iPAT, khususnya tentang informasi anatomi (clinical image quality). Akan tetapi hal ini belum teruji secara statistik.

\section{METODE}

Penelitian ini merupakan penelitian eksperimental dengan pendekatan kualitatif yang bertujuan untuk mengetahui ada atau tidaknya perbedaan kualitas informasi anatomi citra MRI Lumbal sekuens turbo spin echo (TSE) pembobotan $\mathrm{T} 1$ dan $\mathrm{T} 2$ potongan sagital antara teknik rutin dengan teknik parallel imaging metode mSENSE dan metode GRAPPA

Setelah dihasilkan citra dari 10 pasien, kemudian dilakukan evaluasi oleh dokter spesialis radiologi menggunakan kuisioner. Skor hasil penilaian oleh responden kemudian diolah secara deskriptif dan statistik. Uji statistik dilakukan dengan Uji Friedman untuk mengetahui perbedaan antara ketiga perlakuan. Kemudian dilakukan post hoc dengan uji Wilcoxon untuk mengetahui perbedaan antar dua kelompok sampel.

\section{HASIL}

Pada table 1 dapat dilihat bahwa scan time dengan teknik parallel imaging baik metode mSENSE akan berkurang 48,39\% dari teknik rutin dan pada metode GRAPPA akan berkurang sekitar 52,09\% dari teknik konvensional TSE. Grafik hasil penilaian skor kualitas informasi anatomi citra MRI yang dinilai secara keseluruhan masing-masing variasi teknik dapat dilihat pada gambar 1, 2, 3, 4, 5, dan 6 .

Berdasarkan tabel 2 menunjukkan bahwa perlakuan metode mSENSE dan GRAPPA dilakukan tanpa mengubah parameter dari teknik konvensional TSE. Accelerating factor ( $R$-factor) merupakan parameter tambahan pada teknik parallel imaging, pada penelitian ini digunakan accelerating factor 2. Contoh citra hasil MRI penelitian dengan teknik rutin, parallel imaging metode mSENSE dan metode GRAPPA dapat dilihat pada gambar 7 dan gambar 8 .
Tabel 1. Reduksi Scan Time

\begin{tabular}{cccccc}
\hline & \multicolumn{3}{c}{ Scan Time } & Reduksi \\
\cline { 2 - 5 } Pembobotan & $\begin{array}{c}\text { Konv }- \\
\text { TSE }\end{array}$ & $\begin{array}{c}\text { Parallel - } \\
\text { mSENSE }\end{array}$ & $\begin{array}{c}\text { Parallel- } \\
\text { GRAPPA }\end{array}$ & $\begin{array}{c}\text { Scan } \\
\text { Time }\end{array}$ & $\%$ \\
\hline T1 & 2.17 & 1.12 & 1.12 & 1.05 & 48.39 \\
T2 & 3.11 & 1.49 & 1.49 & 1.62 & 52.09 \\
\hline
\end{tabular}

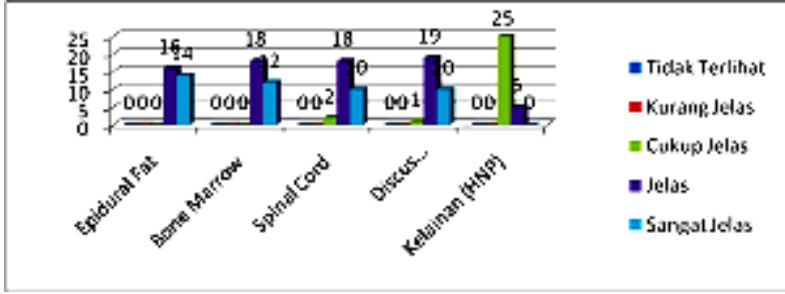

Gambar 1. Grafik teknik Konvensional TSE Pembobotan T1

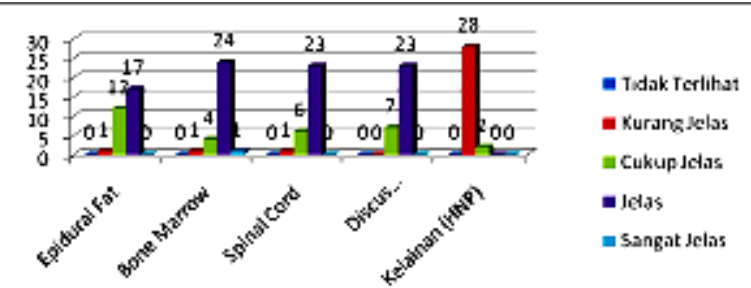

Gambar 2. Grafik parellel imaging metode mSENSE Pembobotan T1

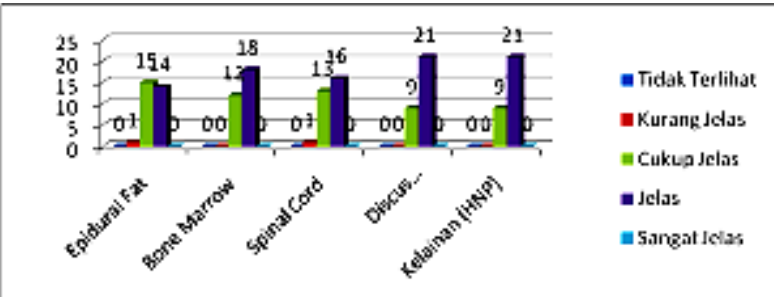

Gambar 3. Grafik parellel imaging metode GRAPPA Pembobotan T1

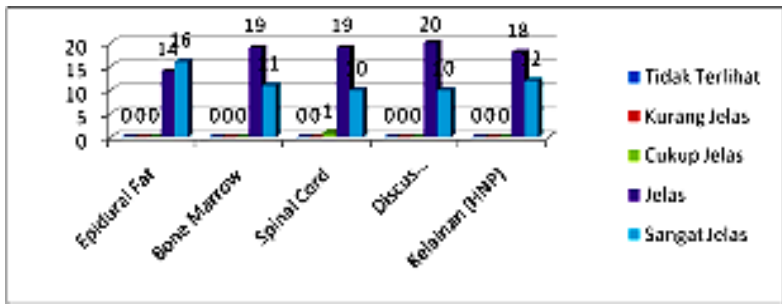

Gambar 4. Grafik teknik Konvensional TSE Pembobotan T2

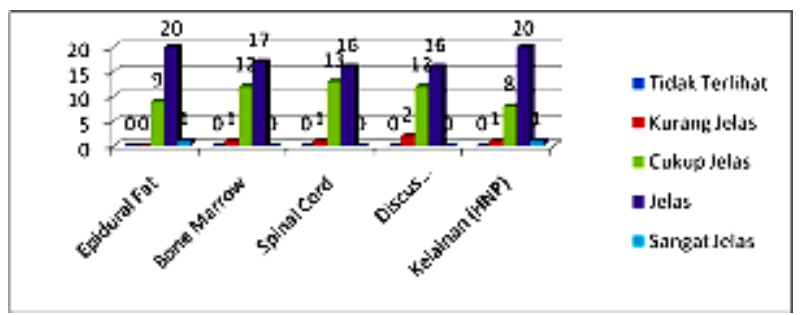

Gambar 5. Grafik parellel imaging metode mSENSE Pembobotan T2 


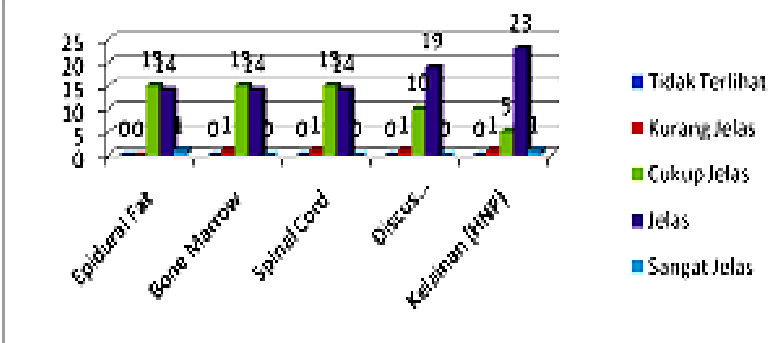

Gambar 6. Grafik Parellel imaging metode GRAPPA Pembobotan T2

Tabel 2. Parameter pemeriksaan MRI Lumbal pembobotan T1 dan $\mathrm{T} 2$ potongan sagital

\begin{tabular}{|c|c|c|c|c|c|c|}
\hline \multirow{2}{*}{ Parameter } & \multicolumn{3}{|c|}{ Pembobotan T1 } & \multicolumn{3}{|c|}{ Pembobotan T2 } \\
\hline & TSE & mSENSE & GRAPPA & TSE & mSENSE & GRAPPA \\
\hline TR (ms) & 397 & 397 & 397 & 3750 & 3750 & 3750 \\
\hline TE (ms) & 15 & 15 & 15 & 99 & 99 & 99 \\
\hline Average & 1 & 1 & 1 & 2 & 2 & 2 \\
\hline $\begin{array}{l}\text { Slice } \\
\text { Thickness } \\
\text { (mm) }\end{array}$ & 4 & 4 & 4 & 4 & 4 & 4 \\
\hline $\begin{array}{l}\text { Arah Phase } \\
\text { encoding }\end{array}$ & $\begin{array}{l}\text { Head- } \\
\text { Feet }\end{array}$ & $\begin{array}{l}\text { Head- } \\
\text { Feet }\end{array}$ & $\begin{array}{l}\text { Head- } \\
\text { Feet }\end{array}$ & $\begin{array}{l}\text { Head- } \\
\text { Feet }\end{array}$ & $\begin{array}{l}\text { Head- } \\
\text { Feet }\end{array}$ & $\begin{array}{l}\text { Head- } \\
\text { Feet }\end{array}$ \\
\hline $\begin{array}{l}\text { Accelerating } \\
\text { factor }\end{array}$ & - & 2 & 2 & - & 2 & 2 \\
\hline
\end{tabular}

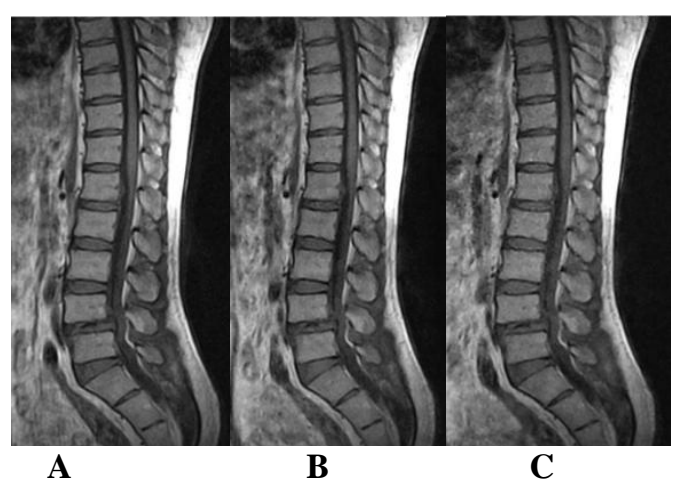

Gambar 7. Contoh Citra MRI hasil penelitian pada pembobotan T1, (A). Teknik konvensional TSE, (B). mSENSE, (C). GRAPPA

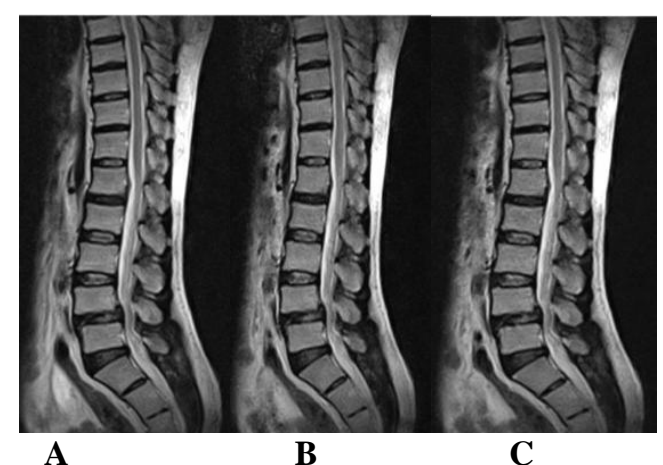

Gambar 8. Contoh Citra MRI hasil penelitian pada pembobotan T2, (A) Teknik konvensional TSE, (B). mSENSE, (C). GRAPPA

\section{PEMBAHASAN}

Pada teknik parallel imaging baik metode mSENSE maupun GRAPPA ada parameter khusus yang dinamakan accelerating factor. Accelerating factor (R-factor) ini menyatakan jumlah coil elemen phased array coils yang akan mempengaruhi scan time (Blaimer dkk, 2004). Variasi $R$ factor ini tergantung dari jumlah coil elemen yang digunakan pada setiap pesawat MRI.

Tabel 3. Hasil Uji Friedman pada keseluruhan informasi anatomi citra MRI pada pembobotan T1

\begin{tabular}{lcccc}
\hline \multicolumn{1}{c}{ Teknik } & $\mathbf{N}$ & $\begin{array}{c}\text { Mean } \\
(\mathbf{m i n}-\mathbf{m a x})\end{array}$ & $\boldsymbol{\rho}$ & Keterangan \\
\hline Konvensional TSE & 150 & $4.12(3-5)$ & $<0.001$ & Ada beda \\
mSENSE & 150 & $3.39(2-5)$ & & \\
GRAPPA & 150 & $3.25(2-4)$ & & \\
\hline
\end{tabular}

Tabel 4. Hasil Uji Friedman pada keseluruhan informasi anatomi citra MRI pada pembobotan T2

\begin{tabular}{lcccc}
\hline \multicolumn{1}{c}{ Teknik } & N & $\begin{array}{c}\text { Mean } \\
(\mathbf{m i n}-\mathbf{m a x})\end{array}$ & $\boldsymbol{\rho}$ & Keterangan \\
\hline $\begin{array}{l}\text { Konvensional } \\
\text { TSE }\end{array}$ & 150 & $4.12(3-5)$ & $<0.001$ & Ada beda \\
mSENSE & 150 & $3.39(2-5)$ & & \\
GRAPPA & 150 & $3.25(2-4)$ & & \\
\hline
\end{tabular}

Tabel 5. Hasil Uji Wilcoxon pada pembobotan T1 untuk keseluruhan skor kualitas informasi anatomi citra MRI

\begin{tabular}{lcc}
\hline \multicolumn{1}{c}{ Teknik } & $\boldsymbol{\rho}$ & Keterangan \\
\hline $\begin{array}{l}\text { Konvensional TSE } \\
\text { - mSENSE }\end{array}$ & $<0.001$ & Ada beda \\
$\begin{array}{l}\text { Konvensional TSE } \\
\text { - GRAPPA }\end{array}$ & $<0.001$ & Ada beda \\
mSENSE - & 0.001 & Ada beda \\
GRAPPA & & \\
\hline
\end{tabular}

Tabel 6. Hasil Uji Wilcoxon pada pembobotan T2 untuk keseluruhan skor kualitas informasi anatomi citra MRI

\begin{tabular}{lcc}
\multicolumn{1}{c}{ Teknik } & $\boldsymbol{\rho}$ & Keterangan \\
\hline Konvensional & $<0.001$ & Ada beda \\
TSE - mSENSE & & Ada beda \\
Konvensional & $<0.001$ & Tidak ada beda \\
TSE - GRAPPA & & \\
mSENSE - & 0.505 & \\
GRAPPA & & \\
\hline
\end{tabular}

Penelitian ini menggunakan pesawat MRI 0,35 tesla yang hanya menggunakan coil dengan 2 elemen, sehingga hanya terdapat ada satu $R$-factor yaitu 2 . Sehingga penelitian ini tidak bisa untuk menilai pengaruh dari $R$-factor baik terhadap scan time maupun kualitas citra. Maka alangkah baiknya jika penelitian ini dilanjutkan pada pesawat MRI yang lain dengan tesla yang lebih tinggi misalnya, yang memiliki variasi $R$-factor yang lebih banyak untuk mengetahui 
pengaruh dari $R$-factor tersebut pada masing-masing metode parallel imaging.

Uji beda secara statistik dilakukan dengan uji Friedman untuk mengetahui perbedaan ketiga teknik tersebut. Kemudian dilanjutkan dengan uji post hoc Wilcoxon untuk mengetahui perbedaan dari ketiga teknik tersebut dengan dibedakan satu persatu untuk setiap dua teknik. Hasil uji Friedman menunjukkan ada perbedaan dari ketiga teknik pada semua pembobotan (tabel 3 dan tabel 4). Hal ini berarti bahwa $\mathrm{H}_{0}$ ditolak dan $\mathrm{H}_{\mathrm{a}}$ diterima.

Untuk hasil uji Wilcoxon pada pembobotan T1 (tabel 5) didapatkan ada perbedaan pada semua kriteria yang dinilai antara teknik konvensional TSE dengan teknik mSENSE dan antara teknik rutin dengan GRAPPA. Sedangkan antara mSENSE dan GRAPPA, pada epidural fat, discus intervertebralis dan kelainan (HNP) tidak terdapat perbedaan. Hal ini menunjukkan teknik mSENSE dan GRAPPA memiliki kemampuan untuk manampilkan organ tersebut secara sama, dalam arti kejelasan organ tersebut. Hal ini sedikit berbeda dengan penelitian-penelitian yang dilakukan sebelumnya yang menyebutkan tidak ada perbedaan yang signifikan antara teknik konvensional TSE dengan teknik parallel imaging baik mSENSE maupun GRAPPA. Seperti penelitan yang dilakukan Ruel dkk (2004) yang menyebutkan teknik parallel imaging baik mSENSE maupun GRAPPA memberikan SNR dan informasi citra yang tidak berbeda dengan teknik T2W Fast Spin Echo konvensional.

Pada pembobotan T2, hasil uji Wilcoxon didapatkan hasil $\rho<0,05$ yang berarti ada perbedaan antara teknik rutin dengan mSENSE, dan teknik rutin dengan GRAPPA, tetapi antara mSENSE dengan GRAPPA nilai $\rho>0,05$ yang artinya tidak ada perbedaan yang signifikan pada kesemua organ/kriteria yang dinilai. Hal ini didasari oleh karena Parallel imaging metode mSENSE merupakan teknik yang rekonstruksi citranya terjadi pada image setelah transformasi Fourier, sedangkan teknik GRAPPA rekonstruksi terjadi di k space sebelum transformasi Fourier (Blaimer, 2004). Secara visual kasat mata perbedaan dari kedua teknik ini mungkin saja tidak terlihat secara nyata oleh mata manusia.Tetapi secara teknik dan teoritis kedua teknik ini sedikit berbeda konsep rekonstruksi citranya. Akan tetapi secara akuisisi kedua teknik ini sama-sama memanfaatkan phased array coil atau multi chanel coil elemen dengan teknik undersampling.

\section{SIMPULAN}

Ada perbedaan yang signifikan antara teknik konvensional TSE dengan teknik parallel imaging metode mSENSE dan GRAPPA baik pada pembobotan T1 maupun T2 dengan nilai $\rho<0,05$ pada uji Friedman. Sedangkan dari hasil uji post hoc Wilcoxon, didapatkan hasil tidak ada perbedaan yang signifikan hanya pada pembobotan T2 antara teknik parallel imaging metode mSENSE dengan metode GRAPPA. Hasil mean rank menunjukkan teknik konvensional TSE lebih baik dari kedua teknik parallel imaging. Teknik mSENSE lebih baik dari teknik GRAPPA.

Maka dari itu, untuk pasien-pasien dengan tingkat kesakitan yang cukup tinggi seperti pada kasus HNP yang memungkinkan terjadinya pergerakan pasien sebaiknya diterapkan parallel imaging metode mSENSE untuk mengurangi waktu pemeriksaan. Untuk mendapatkan hasil citra MRI dengan detail yang tinggi sebaiknya digunakan teknik konvensional TSE dengan konekuensi waktu scan yang lebih lama jika dibandingkan dengan teknik parallel imaging.

\section{DAFTAR PUSTAKA}

Blaimer, Martin. et al. 2004. SMASH, SENSE, PILS, GRAPPA: How to Choose the Optimal Method. Top Magn Reson Imaging, Volume 15 Number 4.

Griswold, Mark A. et al. 2002. Generalized Autocalibrating Partially Parallel Acquisitions (GRAPPA). Magnetic Resonance in Medicine 47:12021210

Larkman, David J and Nunes, Rita G. 2007. Parallel magnetic resonance imaging. London: The Imaging Sciences Department, Clinical Sciences Centre, Faculty of Medicine, Imperial College London.

McRobbie, D. W. et al. 2006. MRI From Picture to Proton, Second edition. United States of America by Cambridge University Press, New York.

Nölte, Ingo. et al. 2008. MRI of degenerative lumbar spine disease: comparison of non-accelerated and parallel imaging . Neuroradiology (2008) 50:403-409. Springer-Verlag.

Pallamar, J. Fruehwald. et al. 2012. Parallel Imaging of the Cervical Spine at 3T: Optimized Trade-Off between Speed and Image Quality. AJNR Am J Neuroradiol 33:1867-74.

Pruessmann, Klaas P. 1999. SENSE: Sensitivity Encoding for Fast MRI Magnetic Resonance in Medicine 42:952-962.

Ruel, Lucile. et al. 2004. Comparison of In Vitro and In Vivo MRI of the Spine Using Parallel Imaging. AJR 2004;182:749-755.

Wang, Haifeng. et al. 2010. Cross-Sampled GRAPPA for Parallel MRI. USA: University of Wisconsin.

Weishaupt, Dominik. et al. 2006. How Does MRI Work? An Introduction to the Physics and Function of Magnetic Resonance Imaging, Second Edition. ISBN-13 978-3-540-30067-0 Springer Berlin Heidelberg New York.

Westbrook, Chaterine and Kaut, Carolyne. 2011. MRI in Practice, Second Edition. Blackwell Science Ltd : United Kingdom. 